\title{
THE RELATIONSHIP BETWEEN CORPORATE SOCIAL RESPONSIBILITY ORIENTATION IN HUMAN RESOURCE MANAGEMENT AND EFFECTIVENESS OF PRIVATE HOSPITAL IN THAILAND
}

Sumittra Jirawuttinunt, Mahasarakham Business School, Mahasarakham University, Thailand Kannika Janepuengporn, Mahasarakham Business School, Mahasarakham University, Thailand

\author{
dx.doi.org/10.18374/IJBS-13-4.9
}

\begin{abstract}
The purpose in this study is to examine the relationships between corporate social responsibility orientation (economic, moral, social, environment and legal) in HRM and organizational effectiveness via organizational trust, organizational commitment and organizational citizenship behavior. Here, 131 private hospitals in Thailand are chosen as the sample of the study. According to medical service business in Thailand, the results of OLS regression analysis indicate that five dimensions of CSR in HRM have significant influence on organizational trust, organizational commitment, organizational citizenship behavior and organizational effectiveness. Potential discussion with the research results is effectively implemented in the research. Theoretical and managerial contributions are explicitly provided. Conclusion and directions of the future research are highlighted.
\end{abstract}

Keywords: Corporate Social Responsibility, Human Resource Management, Organizational Trust, Organizational Commitment, Organizational Citizenship behavior, and Organizational Effectiveness, 